\title{
A Comparative Analysis on the Wealth Effect between in the Stock Market and in the Housing Market in China
}

\author{
Lin $\operatorname{Liu}^{1} \&$ Kai Shi ${ }^{1}$ \\ ${ }^{1}$ School of Economics, Northeast Normal University, Changchun, China \\ Correspondence: Kai Shi, School of Economics, Northeast Normal University, 2555 Jingyue Street, Changchun, \\ P.R. China. Tel: 86-0431-8453-6992. E-mail: shik142@nenu.edu.cn
}

Received: September 11, 2017

Accepted: September 28, 2017

Online Published: October 15, 2017

doi:10.5539/ijef.v9n11p118

URL: https://doi.org/10.5539/ijef.v9n11p118

\begin{abstract}
In this article, a threshold cointegration test within the framework of Autoregressive Distributed Lag model suggested by $\mathrm{Li}$ and Lee (2010) was employed to quantify the wealth effects in Chinese stock market and domestic housing market. The time-varying features of wealth effects in these two markets were investigated through rolling regression test. The empirical results show that the substitute effect exists in the status of strong market while the wealth effect exists in the status of weak market. It is noteworthy that the wealth effect in the stock market shows an increasing trend while the wealth effect in the housing market reveals a stable trend. The policy implication is that the authority should properly strengthen the regulation in the stock market and curb the rise of housing price when the markets are in the strong status while should increase the disposable income for residents if the markets are in the weak status.
\end{abstract}

Keywords: ADL tests for threshold cointegration, stock market wealth effect, housing market wealth effect, rolling regression

\section{Introduction}

Wealth effect is what directions and magnitudes the wealth affects the consumption. With the Chinese stock and housing markets developing rapidly in recent years, we mainly compare the stock market wealth effect with the housing market wealth effect for China.

Previous scholars have carried out numerous studies on the stock market wealth effect and housing market wealth effect (see Literature and Hypotheses). However, there are two unsolved empirical research problems. Firstly, most studies mainly focus on the linear relationship between stock wealth, housing wealth and consumption. On the contrary, latest works have indicated different market conditions influenced investor sentiments, which could cause asymmetric investment behavior (Stambaugh et al., 2012; Jsai, 2016). In other words, the changes of the stock and housing market conditions may cause nonlinear relationship between consumption and stock wealth and housing wealth. According to this, we propose the first hypothesis. Secondly, most existing literature about Chinese wealth effect neglect the change of structure over time, therefore, we propose the second hypothesis.

To verify the first hypothesis, which investigates nonlinear relationship between Chinese stock wealth, housing wealth and consumption, we employ threshold cointegration method. Given that size distortions and power loss in some past methods (Perron, 1989; Seo, 2006), we employ threshold cointegration in autoregressive distributed lag (ADL) model proposed by Li and Lee (2010). Firstly, before carrying out formal tests, we use preliminarily the autocorrelation function and contemporaneous cross-correlation values to get a sense of data. Secondly, we conduct formal unit root and threshold cointegration tests. To verify the existence of unit roots, we apply ADF, PP and KPSS tests. Additionally, to investigate the nonlinear relationship between consumption, Chinese stock and housing wealth, we apply ADL tests for threshold cointegration. Lastly, we employ rolling regression to verify the second hypothesis, which analyzes time-varying wealth effect of the Chinese stock and housing markets.

Our results show: 1) Compared with the positive and great housing market wealth effect, the stock market wealth effect is negative and small, the possible reasons are excessive speculation, low returns and high fluctuations of the stock market. In addition, due to limited number of financial assets, consumption is mainly affected by residents' income. 2) There exists a nonlinear relationship between consumption, stock wealth and housing 
wealth. Specifically, substitute effect exists in strong markets, however, wealth effect exists in weak markets. The reasons behind this phenomenon could be partly due to that the changes of the stock and housing market conditions lead to asymmetric investment behavior. 3) In the whole sub-samples, the stock market wealth effect displays an increasing trend while dissimilarly, the housing market wealth effect shows a stable trend. The former is ascribed to the reforming of the stock market and the latter indicates the house property is still valuable to hold.

Our work can make up the lack of existing studies in a nonlinear relationship between consumption, stock wealth and housing wealth. In addition, we analyze the structural changes of wealth effect of Chinese stock and housing markets, which is almost neglected in all other works.

The rest of our article is constructed as follows. Section II reviews the literature and proposes two hypotheses. Section III describes the theoretical model. Section IV reports the empirical results. The conclusion is shown in the section V.

\section{Literature Review and Hypothesis}

In this section, we briefly review previous studies on wealth effect, and then propose two hypotheses.

\subsection{Literature Review}

The effects of the wealth on consumption were first studied by Keynes (1936). After that, Haberler (1939) defined this relationship between consumption and wealth as real-balance effect or wealth effect. Subsequently, a great number of scholars proceeded to investigate wealth effect.

Since the stock market has been increasingly important, early scholars mainly focused on the stock market wealth effect. A number of researches have verified the stock market had a significant impact on consumption (Levine \& Zervos, 1998; Shirvani \& Wilbratte, 2002) and found the magnitude of the stock market wealth effect varied across western countries (Edison \& Slok, 2001; Bertaut, 2002). Apergis and Miller (2006) maintained the rise and fall of stock prices exerted distinct effects on consumption.

The studies of the housing market wealth effect originated in an interesting economic phenomenon which share prices declined all over the world while consumer spending kept balance in the late 1990's. Scholars assumed the reason of this economic phenomenon was that the positive effect of the housing market on consumption had offset the negative effect of the stock market. Therefore, a number of scholars descended to verify the housing market wealth effect. Boone and Girouard (2002) provided evidence that the magnitude of the housing market wealth effect varied across countries and increased over time. Campbell and Cocco (2004) asserted the impact of house prices on consumption changed across ages, crowds and regions. Chen et al. (2010) maintained house market had an asymmetric impact on consumption under unconstrained and constrained regimes.

Further, a few papers which investigated the relationship between consumption, stock and housing wealth asserted the housing market exert relatively greater wealth effect than the stock market (Case et al., 2005; Benjamin \& Chinloy, 2004). Bayoumi and Edison (2002) not only found the effects of house prices on consumption is greater, but maintained the size of the wealth effect could rise over time. Tsai (2016) verified the consumption level derived from the housing market was relatively higher than the stock market.

In addition, previous studies have employed the linear model to analyze the wealth effect between consumption, stock and housing markets. For example, Boone and Girouard (2002) used the cointegration and error correction model, Campbell and Cocco (2004) employed the baseline regression method and Arnold and Michael (2008) used the vector autoregressive (VAR) approach.

In fact, latest papers have indicated that optimistic and pessimistic investor sentiments generated asymmetric influences on stock returns. For instance, Stambaugh et al. (2012) asserted optimistic sentiment made overpricing more prevalent than pessimistic sentiment made under-pricing. Jsai (2016) also have verified optimistic sentiment produced overinvestment, reducing stock prices in the following periods. This indicated the changes of trader sentiment depending on market conditions may generate asymmetric investment behavior, which could cause asymmetric wealth effect.

To study this asymmetric wealth effect between consumption, stock and housing markets, unlike previous papers have employed the linear model, we construct a nonlinear model based on ADL tests for threshold cointegration. Additionally, few extant studies research time-varying wealth effect for China. Therefore, we use a rolling regression method to investigate the structural changes of wealth effect over time.

\subsection{Hypothesis}

In this section, to investigate asymmetric and time-varying wealth effect, we propose two hypotheses. Firstly, 
given that asymmetric wealth effect relying on different market conditions, we propose the first hypothesis:

Hypothesis 1. The stock and housing markets exert significant effects on consumption in the long term, but the adjustment speed of consumption towards long-equilibrium is asymmetric when market conditions change in the short term.

As mentioned above, past studies have proven wealth effect exists between consumption, stock and housing markets in the long term. However, due to the changes of market conditions, wealth effect may be asymmetric. When the stock market or housing market is strong, the rise of asset prices may generate optimistic sentiment, which increases investment and causes a decline in consumption, namely substitution effect. By contrast, when stock market or housing market is weak, the decline of asset prices may generate pessimistic sentiment, which shrinks wealth and causes a reduction in consumption, namely negative wealth effect.

If the above hypothesis is true, we propose the second hypothesis on time-varying wealth effect:

Hypothesis 2. The Chinese stock market wealth effect and the housing market wealth effect are time-varying.

Given that market conditions have changed in the recent years, we assume the structure of wealth may change over time.

\section{Theoretical Model}

To test the two hypotheses, in this section, we firstly introduce the Life-cycle and Permanent Income Hypothesis (LC-PIH) to describe long-term linear relationship between consumption, stock and housing markets. Based on it, we further follow ADL tests for threshold cointegration to construct asymmetric wealth effect.

\subsection{LC-PIH Theory}

LC-PIH investigated theoretically relationship between total wealth and consumption (Hall, 1987; Flavin, 1981). It is given by:

$$
C_{t}=\alpha Y_{t}+\beta W_{t}+e_{t}
$$

where $C_{t}$ is consumption, $Y_{t}$ is income, $W_{t}$ is total wealth which includes stocks, house property, bonds and so on, $\alpha$ and $\beta$ are marginal propensity to consume (MPC), $t$ is the number of observations.

To further investigate the effects of stock and house prices on consumption, Ludwing and slok (2002) divided total wealth $W_{t}$ into stock wealth and housing wealth, which is given by

$$
W_{t}=S_{t}+H_{t}
$$

where $S_{t}$ is stock wealth and $H_{t}$ is housing wealth. Thus (1) is modified by

$$
C_{t}=\alpha_{0}+\alpha_{1} Y_{t}+\alpha_{2} S_{t}+\alpha_{3} H_{t}+e_{t}
$$

Obviously, (3) shows abstractly that there exist a linear relationship between consumption, stock and housing wealth.

\subsection{ADL Tests for Threshold Cointegration}

To verify the first hypothesis, based on LC-PIH, we use the ADL tests for threshold cointegration model suggested by Li and Lee (2010) to establish a nonlinear relationship between consumption, stock and housing wealth.

ADL tests for threshold cointegration are to establish a threshold vector error-correction model using the ADL model. It shows a good performance to address a nonlinear long-term equilibrium problem because of avoiding common factor restriction (CFR) problem and nuisance parameter dependency problem based on the ECM threshold cointegration tests. For now, we will briefly describe this method.

Firstly, we focus on whether the consumption is cointegrated with stock wealth as well as housing wealth. According to (3), the potential cointegration relationship is written by

$$
C_{t}=\alpha_{0}+\alpha_{1} Y_{t}+\alpha_{2} S_{t}+\alpha_{3} H_{t}+e_{t}
$$

where $\alpha_{0}, \alpha_{1}, \alpha_{2}$ and $\alpha_{3}$ are parameters, $e_{t}$ is error term. Note that $e_{t}$ may be stationary or nonstationary. If $e_{t}$ is stationary, then the cointegration relationship exists in (4). Otherwise, equation (4) is not cointegrated. In this article, threshold variable is given by

$$
e_{t}=C_{t}-\alpha_{0}-\alpha_{1} Y_{t}-\alpha_{2} S_{t}-\alpha_{3} H_{t}
$$

Secondly, we describe the threshold vector error-correction model based on the ADL model. According to (4), ADL model is modified as: 


$$
\begin{aligned}
\Delta C_{t}=\beta_{0}+\beta_{1} t & +\beta_{2} C_{t-1} I_{1 t}+\beta_{3} C_{t-1} I_{2 t}+\beta_{4} Y_{t-1} I_{1 t}+\beta_{5} Y_{t-1} I_{2 t}+\beta_{6} S_{t-1} I_{1 t}+ \\
\beta_{7} S_{t-1} I_{2 t}+ & \beta_{8} H_{t-1} I_{1 t}+\beta_{9} H_{t-1} I_{2 t}+\beta_{10} \Delta C_{t}+\beta_{11} \Delta Y_{t}+\beta_{11} \Delta S_{t}+\beta_{12} \Delta H_{t} \\
& +\sum_{i=1}^{P} \theta_{1} \Delta C_{t-i}+\sum_{i=1}^{P} \theta_{1} \Delta Y_{t-i}+\sum_{i=1}^{P} \theta_{1} \Delta S_{t-i}+\sum_{i=1}^{P} \theta_{1} \Delta H_{t-i}+u_{t}
\end{aligned}
$$

where $\beta_{i}$, for $i=0, \ldots 11,12$, are parameters, $t$ is a trend term, $u_{t}$ is the error term. In order to eliminate autocorrelation from error term, $p$ is the maximum lag length of $\Delta C_{t}$. $\beta_{i}$, for $i=2, \ldots 9$, present adjustment speed to long-term equilibrium.

Two different indicator functions $I_{i t}$, for $i=1,2$, are redefined by Li and Lee (2010). Next, we will describe specifically two indicator functions. One is redefined by

$$
I_{1 t}=I\left(e_{t-1}<e_{t-1}^{*}(\tau)\right), I_{2 t}=1-I_{1 t}
$$

where if $e_{t-1}<e_{t-1}^{*}(\tau), I_{l t}=1$ and $I_{2 t}=0$. Otherwise $I_{1 t}=0$ and $I_{2 t}=1$. Unlike previous form of two indicator functions that threshold value is fixed introduced by Enders and Siklos (2001), in this threshold cointegration model, threshold value $e_{t-1}^{*}(\tau)$ is defined as $\tau-t h$ percentile element of $e_{t-1}$, which is ranked in ascending order. The second indicator function, so-called momentum type, is defined by

$$
\tilde{I}_{1 t}=I\left(\Delta e_{t-1}<\Delta e_{t-1}^{*}(\tau)\right), \tilde{I}_{2 t}=1-\tilde{I}_{1 t}
$$

where $\Delta e_{t-1}$ denotes the first difference of $e_{t-1}, \Delta e_{t-1}^{*}(\tau)$ denotes $\tau-t h$ percentile element of $\Delta e_{t-1}$.

Note that asymptotic distribution of $e_{t-1}$ relies on the $\tau$ ranges, hence threshold parameters can be estimated using the grid search to get a sup Wald type statistic. It is good to use all information included in an asymptotic distribution and control effectively nuisance parameters by the sup Wald type statistic. In addition, the range of $\tau$ is a bounded set $\Theta=[0.15,0.85]$ following Andrews (1993).

\section{Empirical Results}

\subsection{Data}

The data set comprises quarterly data and covers the interval ranging from 2002:1 to 2016:2. We employed four variables. The consumption is represented by total retail sales of consumer goods, the income is represented by disposable income of urban residents, the stock wealth is represented by A-share market capitalization of Shanghai Stock Exchange and housing wealth is represented by average prices of commercial house. The data is sourced from CEIC China Economic Database.

To get real consumption and income data, we process data by consumer price index (CPI) (Note 1). Further, to eliminate seasonal impact on consumption and income data, we follow the Tramo/Seats method. Four variables are taken by logarithm form.

\subsection{Preliminary Tests}

In this part, we use the autocorrelation function values and contemporaneous cross-correlation values to get a basic grasp for the data preliminarily before unit root tests and threshold cointegration tests based on ADL model.

Firstly, given that autocorrelation function values over time measure persistence, we compare it with a

\begin{tabular}{|c|c|c|c|c|c|}
\hline lag & Ln C & Ln Y & Ln S & Ln H & GDP \\
\hline 1 & 0.948 & 0.931 & 0.953 & 0.914 & 0.904 \\
\hline 2 & 0.899 & 0.870 & 0.894 & 0.846 & 0.873 \\
\hline 3 & 0.846 & 0.828 & 0.820 & 0.815 & 0.822 \\
\hline 4 & 0.796 & 0.785 & 0.737 & 0.776 & 0.829 \\
\hline 5 & 0.745 & 0.728 & 0.662 & 0.722 & 0.734 \\
\hline 6 & 0.692 & 0.674 & 0.592 & 0.655 & 0.699 \\
\hline 7 & 0.643 & 0.631 & 0.528 & 0.623 & 0.644 \\
\hline 8 & 0.596 & 0.588 & 0.475 & 0.585 & 0.644 \\
\hline 9 & 0.548 & 0.538 & 0.435 & 0.526 & 0.550 \\
\hline 10 & 0.499 & 0.490 & 0.393 & 0.461 & 0.513 \\
\hline 11 & 0.451 & 0.444 & 0.350 & 0.426 & 0.456 \\
\hline 12 & 0.409 & 0.402 & 0.305 & 0.397 & 0.450 \\
\hline
\end{tabular}
nonstationary series to potentially analyze whether four variables have unit roots. In this article, autocorrelation function values of the GDP series is selected as a reference series. As is shown in Table 1, the persistence of four series is the same as GDP series, hence we preliminarily identify that they have unit roots.

Table 1. Autocorrelation function values 
Secondly, contemporaneous cross-correlation values are used to analyze potentially cointegrated relationship in our study. When two variables exist highly correlationship, it indicates that they are cointegrated. Table 2 describes contemporaneous cross-correlation values for four variables. As is shown in Table 2, four variables are highly positive correlated with each other, which indicates they may be cointegrated.

Table 2. Contemporaneous cross-correlation values

\begin{tabular}{ccccc}
\hline & Ln C & Ln Y & Ln S & Ln H \\
\hline Ln C & 1.000 & 0.975 & 0.868 & 0.975 \\
Ln Y & 0.975 & 1.000 & 0.873 & 0.943 \\
Ln S & 0.868 & 0.873 & 1.000 & 0.867 \\
Ln H & 0.975 & 0.943 & 0.867 & 1.000 \\
\hline
\end{tabular}

\subsection{Unit Root Tests}

Before threshold cointegration tests, unit root tests are employed to identify whether each variable is stationary. Generally speaking, there are three popular methods for unit root tests: Augmented Dickey-Fuller tests (ADF), Phillips-Perron (PP) and Kwiatkowski Phillps Schmidt Shin (KPSS) (Note 2). ADF tests and PP tests employ a null hypothesis of having a unit root and the KPSS tests employ a null hypothesis of having no unit root. As is shown in the Table III, four variables cannot reject the null hypothesis of ADF tests and PP tests, while they can reject significantly the null hypothesis of KPSS tests. Hence, four variables are nonstationary, which consists of the results of preliminary tests. Although they are nonstationary, the results of preliminary tests imply that there exists cointegrated relationship among four variables. As is mentioned above, we assume that there exists the nonlinear relationship between consumption, stock wealth and housing wealth, in order to investigate it, we run threshold cointegration tests based on ADL model below.

Table 3. Unit root test

\begin{tabular}{|c|c|c|c|c|c|c|c|c|c|c|c|}
\hline \multicolumn{3}{|c|}{$\mathrm{LnC}$} & \multicolumn{3}{|c|}{ Ln Y } & \multicolumn{3}{|c|}{ Ln $S$} & \multicolumn{3}{|c|}{$\mathrm{Ln} \mathrm{H}$} \\
\hline trend & cons & none & trend & cons & none & trend & cons & none & trend & cons & none \\
\hline $\mathrm{ADF}$ test & H0:Nonstatiol & arity & & & & & & & & & \\
\hline-1.48 & -1.51 & 1.43 & -0.10 & -2.62 & 2.94 & -2.25 & -1.22 & 0.88 & $-5.75 * * *$ & -0.92 & 3.80 \\
\hline$(-3.50)$ & $(-2.92)$ & $(-1.95)$ & $(-3.50)$ & $(-2.92)$ & $(-1.95)$ & $(-3.50)$ & $(-2.92)$ & $(-1.95)$ & $(-3.50)$ & $(-2.92)$ & $(-1.95)$ \\
\hline PP test & H0:Nonstatio & arity & & & & & & & & & \\
\hline-1.27 & -2.76 & 8.04 & $-4.43 * * *$ & -1.37 & 2.19 & -1.94 & -1.21 & 1.14 & $-5.75 * * *$ & -0.62 & 5.01 \\
\hline$(-3.49)$ & $(-2.91)$ & $(-1.95)$ & $(-3.49)$ & $(-2.91)$ & $(-1.95)$ & $(-3.49)$ & $(-2.91)$ & $(-1.95)$ & $(-3.49)$ & $(-2.91)$ & $(-1.95)$ \\
\hline KPSS test & H0:Stationar & & & & & & & & & & \\
\hline $0.19 * *$ & $0.93^{* * *}$ & & $0.33^{* * *} *$ & $0.91 * * *$ & & $0.14^{*}$ & $0.76^{* * *}$ & & $0.19 * *$ & $0.92 * * *$ & \\
\hline$(0.15)$ & $(0.46)$ & & $(0.15)$ & $(0.46)$ & & $(0.15)$ & $(0.46)$ & & $(0.15)$ & $(0.46)$ & \\
\hline
\end{tabular}

Note. Schwarz Information Criteria (SIC) is employed to determine the optimal lag length of unit root tests. The bandwidth is determined by Barlett Kernel method for PP tests and KPSS tests. For table III-IV, ***, ** and *denote respectively the 0.01, 0.05 and 0.1 significant levels. Trend means model includes a deterministic time trend and a constant, cons means models include only a constant, and none means models include either a deterministic trend or a constant. For contrastive purpose, values in parenthesis represent $5 \%$ critical values.

\subsection{The Results of ADL Threshold Cointegration}

Before running threshold cointegration tests based on ADL model, we need eliminate autocorrelation by making sure of the optimal lag length of $\Delta L n C_{t}$, which we denote by $p$. In this article, the optimal lag length is 0 , namely $p=0$.

We employ BO test (Note 3) proposed by Li and Lee (2010), which tests threshold cointegration relationship based on ADL model. BO tests use a null hypothesis given by

$$
H_{0}: \beta_{2}=\beta_{3}=\beta_{4}=\beta_{5}=\beta_{6}=\beta_{7}=\beta_{8}=\beta_{9}=0
$$

where the null hypothesis represents that there is no threshold cointegration relationship among four variables.

Table 4 reports the results of threshold cointegration. The table is organized by four horizontal panels, with the first sub-panel listing BO statistics and critical values at $1 \%, 5 \%$ and $10 \%$ significant level, with the second sub-panel listing cointegration coefficients and function, with the third sub-panel listing adjustment coefficients at different intervals and with the fourth sub-panel listing SBC values of ADL tests for threshold cointegration 
and traditional cointegration tests proposed by Engle and Granger (1987).

Firstly, the result of BO statistic is 40.16 , which is bigger than 34.99 at $1 \%$ significant level, which implies consumption is threshold cointegrated with stock wealth and housing wealth. At the same time, the fourth sub-panel reports the SBC value of ADL tests for threshold cointegration is -5.835 and the SBC value of traditional cointegration tests is -4.1437 , which suggests ADL tests for threshold cointegration fit data better than traditional cointegration tests.

Secondly, the second sub-panel shows cointegration coefficients for $\mathrm{LnY}, \mathrm{LnS}$ and $\mathrm{LnH}$, which are respectively $1.6140,-0.0424$ and 0.1315 at $1 \%$ significant level. The cointegration coefficients indicate that, in the long run, if residents' income goes up by $1 \%$, then consumption will approximately go up by $1.6140 \%$; if stock wealth goes up by $1 \%$, then consumption will approximately go down by $0.0424 \%$; if housing wealth goes up by $1 \%$, then consumption will approximately go up by $0.1315 \%$. Therefore, wealth effect exists between consumption and stock and housing wealth, which is consistent with other scholars. Note that the stock market wealth effect is negative while the housing market wealth effect is positive, which implies excessive speculation squeezes consumption in Chinese stock market. Furthermore, compared with the stock market wealth effect, the housing market wealth effect is greater, this can be explained by high returns and low fluctuations of the housing market. In addition, consumption is mainly affected by residents' income, this can be caused by limited number of financial assets holding for most Chinese families.

Table 4. The results of threshold cointegration tests

\begin{tabular}{|c|c|c|c|c|c|}
\hline & & & \multicolumn{3}{|c|}{ Critical values } \\
\hline \multicolumn{3}{|c|}{ BO stat $=40.61 * * *$} & $1 \%$ & $5 \%$ & $10 \%$ \\
\hline \multirow{2}{*}{\multicolumn{6}{|c|}{ Cointegration coefficients }} \\
\hline & & & & & \\
\hline$\alpha_{1}$ & \multicolumn{2}{|c|}{$\alpha_{2}$} & \multicolumn{2}{|l|}{$\alpha_{3}$} & $\alpha_{4}$ \\
\hline $1.6140 * * *$ & \multicolumn{2}{|c|}{$-0.0424 * * *$} & \multicolumn{2}{|l|}{$0.1315^{* * * *}$} & $-4.9406^{* * * *}$ \\
\hline \multirow{2}{*}{\multicolumn{6}{|c|}{$\begin{array}{l}\text { Cointegration relationship } \\
n Y_{t}-0.0424 \times \operatorname{LnS}_{t}+0.1315 \times \operatorname{Ln} H_{t}-4.9406\end{array}$}} \\
\hline & & & & & \\
\hline \multicolumn{6}{|c|}{ Adjustment coefficients } \\
\hline interval 1 & $\beta_{2}$ & $\beta_{4}$ & $\beta_{6}$ & & $\beta_{8}$ \\
\hline$\left(\Delta \mathrm{e}_{\mathrm{t}-1} \leq-0.03\right)$ & -0.1756 & 0.4157 & $0.0555^{* *}$ & & $-0.2227 * *$ \\
\hline interval 2 & $\beta_{3}$ & $\beta_{5}$ & $\beta_{7}$ & & $\beta_{9}$ \\
\hline$\left(\Delta \mathrm{e}_{\mathrm{t}-1}>-0.03\right)$ & $-0.0293 *$ & $0.0580^{* *}$ & 0.0045 & & -0.0239 \\
\hline \multicolumn{3}{|c|}{ SBC $($ ADL-TC $)=-5.8535$} & \multicolumn{3}{|c|}{ SBC $(E-G)=-4.1437$} \\
\hline
\end{tabular}

Note. The critical values of BO test for $10 \%, 5 \%$ and $1 \%$ are $26.78,29.58$ and 34.99 , respectively.

Lastly, the third sub-panel describes short-run adjustment coefficients in two intervals, which measure the adjustment speed to long-term equilibrium for each variable. Where $\beta_{2}, \beta_{4}, \beta_{6}$ and $\beta_{8}$ denote respectively adjustment coefficients of consumption, income, stock wealth and housing wealth in the first interval, namely Interval 1. Similarly, $\beta_{1}, \beta_{3}, \beta_{5}$ and $\beta_{7}$ denote adjustment coefficients of four variables above in the second interval, namely Interval 2 . Note that adjustment coefficients for each variable are different in different intervals, this indicates that there is a nonlinear relationship between consumption, stock wealth and housing wealth. To interpret these nonlinear results economically, we start by analyzing the threshold variable. Our threshold variable follows momentum type (Note 4 ) and is rewritten by:

$$
\Delta e_{t-1}=\Delta L n C_{t-1}-\alpha_{0}-\alpha_{1} \Delta L n Y_{t-1}-\alpha_{2} \Delta L n S_{t-1}-\alpha_{3} \Delta L n H_{t-1}
$$

To analyze further, we draw the first order difference of each variable in Figure 3.

As we can see in Figure 1, the tendency of consumption and income is roughly stationary, it means whether or not $\Delta e_{t-1}$ is positive depends on mainly the fluctuations of $\Delta S_{t-1}$ and $\Delta H_{t-1}$. In the Interval $1, \Delta e_{t-1}$ is below the threshold value -0.03 when either $\Delta S_{t-1}$ is well positive or $\Delta H_{t-1}$ is well positive or they jointly are positive (look at shaded areas in Figure 1), namely the stock or housing market is strong. In the Interval 2, $\Delta e_{t-1}$ is above threshold value -0.03 when either $\Delta S_{t-1}$ is well negative or $\Delta H_{t-1}$ is well negative or they jointly are negative, namely the stock or housing market is weak. Next note that $\beta_{2}$ is non-significant but $\beta_{3}$ is significantly negative. It implies that $\Delta \operatorname{Ln} C_{t}$ adjust towards equilibrium at a low speed when the stock or housing market is 
strong but at a high and negative speed when the stock or housing market is weak. Taken together, low speed implies that consumption is large persistence when the stock or housing market is strong and the high and negative speed implies that consumption is little persistence and change inversely when the stock or housing market is weak.

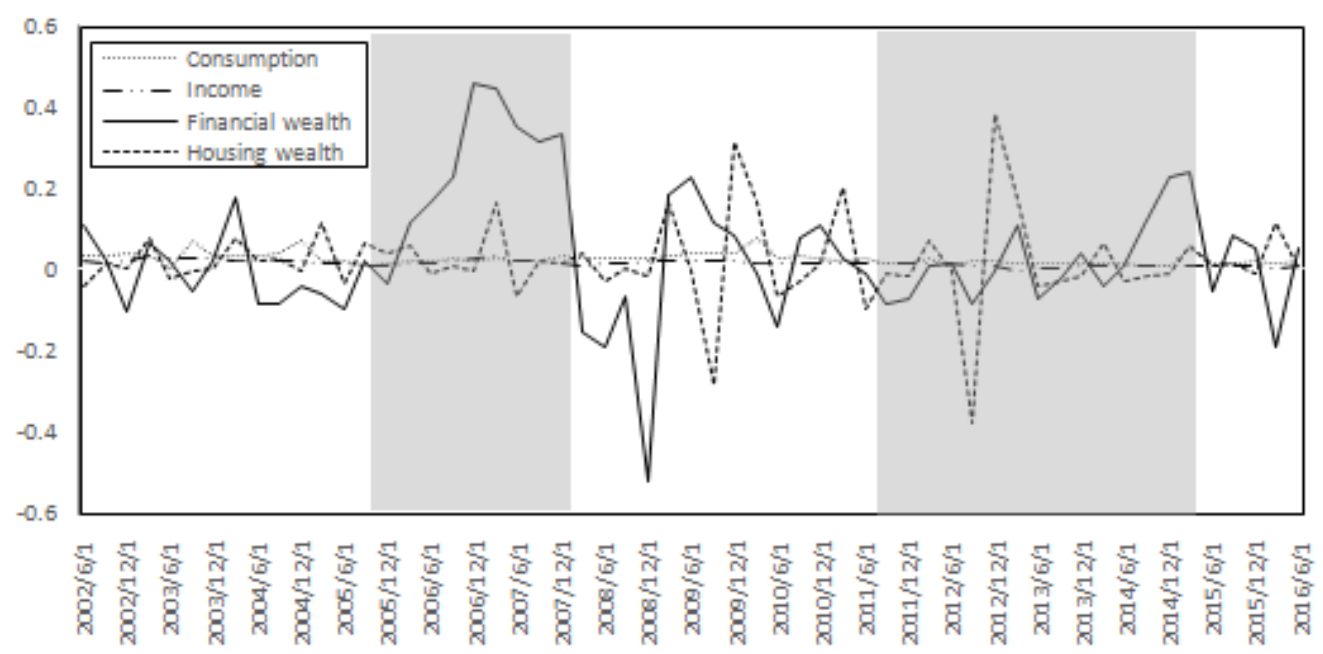

Figure 1. The first difference of four variables diagram

Economically, when stock or housing market is strong, optimistic sentiment could generate overinvestment, which reduces consumption. This leads to a low level of consumption and large persistence. So, when stock or housing market is strong, the investment behavior substitutes the consumption expenditure, namely substitution effect exists in the stock and housing markets. Next note that when the stock or housing market is weak, pessimistic sentiment could decrease investment, which increases disposable income. Therefore, consumption is above average level. However, when the stock or house prices decline during following periods, the decrease of total wealth could lead to the decrease of consumption, thus consumption converges to average level at a high speed. So, when the stock or housing market is weak, the falling of asset prices leads to shrink the wealth, which reduces consumption, namely wealth effect exists in the stock and housing markets.

The asymmetric wealth effect has the impact on setting policies. When the stock or housing markets are strong, to prevent overinvestment from curbing consumption, the authority should strengthen the regulation of stock market and curb the rapid rise in house prices. Also, when stock or housing markets is weak, to stimulate consumption, governors should lift resident's income level.

\subsection{The Results of Rolling Regression}

Further, to test the changes of long-term relationship between consumption and stock and housing wealth, we employ rolling regression methodology, the lterated cumulative sum of squares (ICSS).

In this article, the sample is partitioned into 29 sub-samples, each sub-sample includes 30 quarterly observations (more than 7 years). We use the Ordinary Least Squares (OLS) regressive analysis for each sub-sample in rolling windows. Each following sub-sample is pushed back 1 observation related to preceding period (which is equivalent to one quarter).

Figure 2 shows the time-varying wealth effect, we can draw the following conclusions: (i) The stock market wealth effect displays an increasing trend in the whole sub-samples. In the first twenty sub-samples, stock wealth is negatively correlated with consumption, however, this relationship becomes positive in the remaining sub-samples, which is related with improvement of the stock market. (ii) In the whole sub-samples, the house wealth is positively correlated with consumption. In the first 16th sub-samples, the housing market wealth effect shows an increasing trend, however, trend becomes stable in the later sub-samples, which indicates house property is still valuable to hold. (iii) In the whole sub-samples, the house market wealth effect is greater than the stock market wealth effect, as mentioned above, the reason is the low fluctuations and high returns of the housing market. 


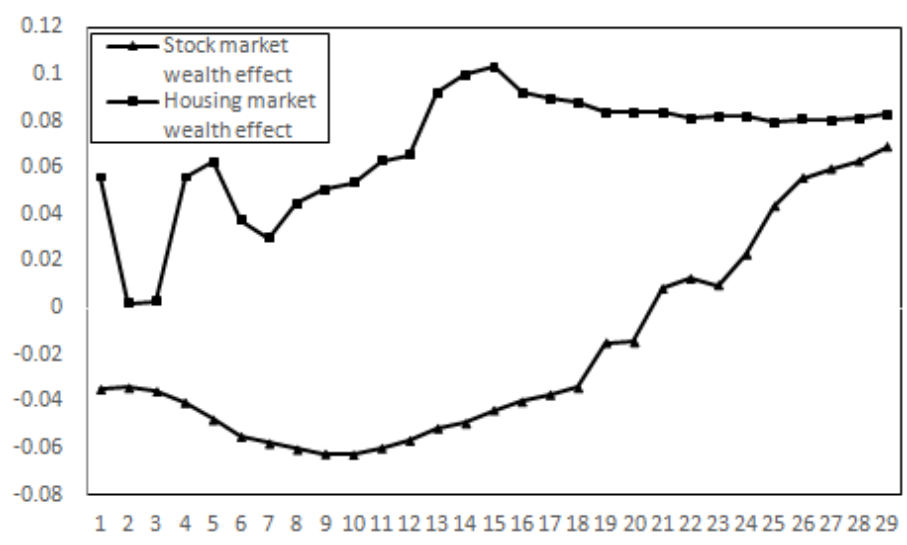

Figure 2. The time-varying wealth effect

In sum, results of ADL tests for threshold cointegration confirm long-term cointegrated relationship and short-term asymmetric wealth effect between consumption, stock and housing wealth. The results of rolling regression verify time-varying wealth effect for Chinese stock and housing markets. These verify hypothesis 1 and 2 .

\section{Discussion}

The wealth effect in financial markets is of importance to the long-run development and the functioning of capital markets. Previous studies have applied a linear model to examine this issue but it may bias real results if a nonlinear relationship exists among consumption and two markets. Our viewpoint is from the studies which have verified that different economic shocks may generate optimistic or pessimistic sentiment and cause asymmetric investment behavior, which may generate asymmetric wealth effect.

To study asymmetric and time-varying wealth effect of stock and housing markets, we firstly propose two hypotheses. The first hypothesis is asymmetric wealth effect exists in stock and housing markets. The second hypothesis is that structure of the wealth effect changes over time. In this article, we firstly employ ADL tests for threshold cointegration to verify the first hypothesis. Furthermore, we employ rolling regression to test the second hypothesis. The empirical results reveal that substitute effect exists in strong markets and wealth effect exists in weak markets. In addition, evidence from the rolling regression points out that the stock market wealth effect displays a increasing trend, dissimilarly, the housing market wealth effect shows a stable trend. Therefore, policy makers should strengthen the regulation of the stock market and curb higher house prices in strong markets and lift resident's income level in weak markets.

\section{Acknowledgments}

This research was financially supported by the Ministry of Education Humanities \& Social Science Fund under Grant No. 15YJC790086; Jilin Social Science Fund under Grant No. 2014B40; Jilin Scientific Development Plan under Grant No. 20150418048FG and Jilin Education Department the 12th Five-year Plan Social Science Research Project 2015-555.

\section{References}

Andrews, D. (1993). Tests for Parameter Instability and Structural Change with Unknown Change Point. Econometrica, 61, 821-856. https://doi.org/10.2307/2951764

Apergis, N., \& Miller, S. M. (2005). Resurrecting the wealth effect on consumption: Further analysis and extension. Retrieved from http://www.econ.uconn.edu./

Arnold, C. S., \& Michael, K. F. (2008). Financial market and housing wealth effects on consumption: A permanent income approach. http://dx.doi.org/10.1080/00036840600994021

Bayoumi, T., \& Edison, H. (2003). Is wealth increasingly driving consumption? Dnb Staff Reports.

Benjamin, J. D., Chinloy, P., \& Jud, G. D. (2004). Real estate versus financial wealth in consumption. The Journal of Real Estate Finance and Economics, 29(3), 341-354. https://doi.org/10.1023/B:REAL.0000036677.42950.98

Bertaut, C. C. (2002). Equity prices, household wealth, and consumption growth in foreign industrial countries: Wealth effects in the 1990s. SSRN Electronic Journal, 131(Suppl. 1, No. 724), 305-321. 
https://doi.org/10.2139/ssrn.307800

Boone, L., \& Girouard, N. (2002). The Stock Market, the Housing Market and Consumer Behaviour. OECD Economic Studies, 2002(2), 12.

Campbell, J. Y., \& Cocco, J. F. (2004). How do house prices affect consumption? Evidence from micro data. https://doi.org/10.2139/ssrn.607161

Case, K. E., Quigley, J. M., \& Shiller, R. J. (2005). Comparing wealth effects: The stock market versus the housing market. https://doi.org/10.2202/1534-6013.1235

Chen, N. K., Chen, S. S., \& Chou, Y. H. (2010). House prices, collateral constraint, and the asymmetric effect on consumption. Journal of Housing Economics, 19(1), 26-37. https://doi.org/10.1016/j.jhe.2009.10.003

Dickey, D. A., \& Fuller, W. A. (1979). Distribution of the Estimators for Autoregressive Time Series with a Unit Root. http://dx.doi.org/0.1080/01621459.1979.10482531

Edison, H. J., \& Slok, T. (2001). Wealth effects and the new economy. http://dx.doi.org/10.2139/ssrn.276082

Engle, R. F., \& Granger, C. W. J. (1987). Cointegration and Error Correction: Representation, Estimation and Testing. Econometrica, 55, 251-276. https://doi.org/10.2307/1913236

Flavin, M. A. (1981). The adjustment of consumption to changing expectations about future income. http://dx.doi.org/10.1086/261016

Haberler, G. (1939). Prosperity and Depression. League of Nations.

Hall, R. E. (1987). Consumption. NBER Working Papers, 98(5), 1887-1921. https://doi.org/10.3386/w2265

Keynes, J. M. (1936). The General Theory of Employment Interest and Money. China Social Sciences Publishing House.

Kremers, J. J. M., Ericsson, N. R., \& Dolado, J. J. (1992). The Power of Cointegration Tests. Oxford Bulletin of Economics and Statistics, 54(3), 325-348. https://doi.org/10.1111/j.1468-0084.1992.tb00005.x

Kwiatkowski, D., Phillips, P. C., Schmidt, P., \& Shin, Y. (1992). Testing the Null Hypothesis of Stationarity against the Alternative of a Unit Root: How Sure are We that Economic Time Series Have a Unit Root? Journal of Econometrics, 54, 59-178. https://doi.org/10.1016/0304-4076(92)90104-Y

Levine, R., \& Zervos, S. (1996). Stock markets, banks, and economic growth. American Economic Review, 88, 537-558.

Li, J., \& Lee, J. (2010). ADL tests for threshold cointegration. Journal of Time, 31(4), 241-254. https://doi.org/10.1111/j.1467-9892.2010.00659.x

Ludwig, A., \& Slok, T. (2001). The impact of stock prices and house prices on consumption in OECD countries. IMF Working Paper, 10, 29-31.

Perron, P. (1989). The calculation of the limiting distribution of the least-squares estimator in a near-integrated model. Econometric Theory, 5(2), 241-255. http://dx.doi.org/10.1017/S026646660001241X

Phillips, P. C., \& Perron, P. (1988). Testing for a Unit Root in Time Series Regression. Biometrika, 75, 335-346. http://dx.doi.org/10.1007/978-94-015-7819-6_2

Seo, M. (2006). Bootstrap testing for the null of no cointegration in a threshold vector error correction model. Journal of Econometrics, 134(1), 129-150. https://doi.org/10.1016/j.jeconom.2005.06.018

Shirvani, H., \& Wilbratte, B. (2002). The wealth effect of the stock market revisited. Journal of Applied Business Research, 18(2), 9-14.

Stambaugh, R. F., Yu, J., \& Yuan, Y. (2012). The short of it: Investor sentiment and anomalies. Journal of Financial Economics, 104(2), 288-302. https://doi.org/10.1016/j.jfineco.2011.12.001

Tsai, I. C. (2016). Wealth effect and investor sentiment. North American Journal of Economics and Finance, 38, 111-123. http://dx.doi.org/10.1016/j.najef.201609.001

\section{Notes}

Note 1. Please refer to Kremers et al. (1992).

Note 2. CPI data is from CEIC Chinese database, which is based on last year prices. 
Note 3. Please refer to Dickey and Fuller (1979), Phillips and Perron (1988) and Kwiatkowski et al. (1992).

Note 4. About the establish of BO statistic, please refer to Li and Lee (2010).

Note 5. Empirical results show that the threshold variable without "momentum type" can not reject the null of BO tests, so these empirical results are not listed in Table IV.

\section{Copyrights}

Copyright for this article is retained by the author(s), with first publication rights granted to the journal.

This is an open-access article distributed under the terms and conditions of the Creative Commons Attribution license (http://creativecommons.org/licenses/by/4.0/). 